\title{
ILCEA
}

Revue de l'Institut des langues et cultures

d'Europe, Amérique, Afrique, Asie et Australie

$11 \mid 2009$

Langues \& cultures de spécialité à l'épreuve des

médias

\section{Texte de cadrage}

\section{Valéry Kossov et Élisabeth Lavault-Olléon}

\section{(2) OpenEdition}

Journals

Édition électronique

URL : http://journals.openedition.org/ilcea/110

DOI : 10.4000/ilcea.110

ISSN : 2101-0609

Éditeur

UGA Éditions/Université Grenoble Alpes

Édition imprimée

ISBN : 978-2-84310-179-3

ISSN : 1639-6073

Référence électronique

Valéry Kossov et Élisabeth Lavault-Olléon, "Texte de cadrage », ILCEA [En ligne], 11 | 2009, mis en ligne le 30 avril 2009, consulté le 08 mars 2021. URL : http://journals.openedition.org/ilcea/110 ; DOI :

https://doi.org/10.4000/ilcea.110

Ce document a été généré automatiquement le 8 mars 2021

(C) ILCEA 


\title{
Texte de cadrage
}

\author{
Valéry Kossov et Élisabeth Lavault-Olléon
}

1 Les rapports entre le monde de la politique et celui des médias ne cessent d'évoluer au tournant $\mathrm{du} \mathrm{xxI}^{\mathrm{e}}$ siècle. Le $4^{\mathrm{e}}$ pouvoir, traditionnellement considéré dans les pays démocratiques comme un moyen d'expression des citoyens, semble souvent se rapprocher des autres branches du pouvoir, au risque de perdre progressivement «sa fonction essentielle de contre-pouvoir $»^{1}$. La construction de l'image des personnalités politiques par les médias est une question très vaste sur laquelle plusieurs domaines de connaissances peuvent converger. Elle implique d'analyser le recours aux diverses stratégies de communication et de relations publiques, voire de manipulation et de propagande.

2 La présente étude se limite à un cas illustrant la formation de l'image dans les textes de la presse écrite. L'influence que peut avoir l'écrit sur l'image est perçue aussi bien par les journalistes que par les politiciens. Ces derniers, en fonction de leurs objectifs, disposent de plusieurs possibilités, parmi lesquelles se trouve d'abord la constitution d'une image sur commande, moins efficace aujourd'hui cependant, étant donné la multiplication des médias et la rapidité de la diffusion des informations. Ensuite, le service de communication peut manipuler les médias par des moyens divers, allant du tri sélectif de l'information jusqu'à la mise à disposition d'informations provocatrices ou fausses. Les médias, quant à eux, ont leurs propres engagements et opinions. Au sein de ces rapports complexes et parfois antinomiques entre le monde des médias et la politique, le troisième acteur est bien entendu, le public qui assiste au spectacle pour se tenir informé et se faire une opinion personnelle ou pour adopter une opinion commune, véhiculée par les journalistes et pouvant alors relever de «la pensée unique $»^{2}$.

3 C'est en nous identifiant à ce troisième acteur que nous abordons l'étude collective et multilingue du processus de la construction d'image, en prenant pour objet celle de la figure controversée de Vladimir Poutine. Nous étudierons comment un discours marquant a été rapporté dans la presse occidentale, en nous fondant sur la transcription du discours original. Cette tâche ambitieuse est portée par la dynamique du multiculturalisme et du multilinguisme. 
4 En effet, le choix d'examiner la presse de plusieurs pays répond au besoin d'objectivité et s'inscrit dans l'approche comparative et transversale de notre étude. L'attitude très critique des journalistes occidentaux vis-à-vis du président Poutine n'est un secret pour personne et l'image véhiculée de ce dernier a toujours été négative, bien avant son élection à ce poste. C'était celle d'une personne froide et autoritaire, qui avait relancé la guerre en Tchétchénie, celle d'un ancien officier du KGB à la politique internationale menaçante, enfin celle d'un fossoyeur impitoyable de l'opposition et des droits et libertés individuelles en Russie. La déconstruction «scientifique » de cette image qui s'est imposée depuis de longues années dépasse le cadre de cette étude. Cependant, il est possible de repérer les procédés à l'œuvre dans la représentation de cet homme politique en se fondant sur les interventions personnelles du président à l'occasion des conférences de presse, comme ce fut le cas à la veille du G8 le $1^{\mathrm{er}}$ juin 2007.

5 Vladimir Poutine est un habitué des conférences de presse. Au cours de ses deux mandats présidentiels (huit ans), il en a organisé au moins une par an en Russie pour les médias russes et étrangers en plus des conférences de presse organisées à l'occasion de certains événements internationaux importants.

On pourrait penser que, à la différence des articles, les publications des conférences de presse donnent la traduction des réponses du président aux questions des journalistes étrangers sans qu'il y ait un jugement de valeur ou l'opinion du journaliste. La mise en situation devrait être réelle et objective, car elle est supposée être, dans ces cas-là, la retranscription écrite du document télévisuel. C'est en tout cas l'idée que se fait un lecteur lambda en ouvrant son journal.

7 Les articles que nous présentons dans cette deuxième partie sont le résultat d'une collaboration multilingue menée depuis plusieurs années par les membres du GREMUTS pour construire une recherche collective autour des enjeux linguistiques et culturels internationaux. Cette recherche porte à la fois sur l'analyse du discours, sur les procédés, stratégies et fonctions de la traduction en situation multilingue et sur les divergences et rapprochements des représentations entre différentes langues et cultures. L'équipe regroupe des enseignants-chercheurs en anglais, allemand, espagnol, italien et russe et a adopté une démarche comparatiste et interactive.

8 La conférence de presse que nous avons choisie comme exemple, s'est tenue le $1^{\text {er }}$ juin 2007 en Russie à la veille d'un sommet du G8 en Allemagne. Le choix de cette conférence s'explique par sa large diffusion dans la presse des huit États membres dont les journalistes ont été conviés à poser leurs questions au président russe dans sa résidence de Novo-Ogarevo (connue, entre autres, comme lieu de réception et de rencontres des hôtes de haut rang du président russe). La publication des extraits de cette conférence de presse a donné lieu à une polémique assez vive sur les relations entre la Russie et l'Occident. Des réactions ont été exprimées en France à la suite de la publication du Figaro représentant ce pays à Moscou. En plus de ce média, la conférence a été couverte par les journaux et périodiques suivants: les quotidiens britannique Times et américain Wall Street Journal, l'hebdomadaire allemand Der Spiegel et les journaux italien et espagnol Corriere Della Sera et El Mundo. Le procès-verbal de la conférence, accessible sur Internet dans ses versions russe et anglaise que nous avons jugées équivalentes, représente le texte source et constitue la base de notre travail d'analyse comparative du discours des intervenants et, plus particulièrement, des réponses de Vladimir Poutine. Il nous a également semblé pertinent, pour la 
construction de l'image, de nous pencher sur les mises en situation réalisées par les journalistes pour créer - ou recréer - l'atmosphère générale.

9 La question qui s'est posée au commencement de cette étude était de savoir comment était effectuée la traduction des réponses et quel en était le degré de fidélité par rapport à l'original. Mais au fur et à mesure de l'avancement des travaux, il s'est avéré qu'il n'était pas tant question de traduction que d'une restructuration sélective du discours de l'original. Et nous nous sommes alors interrogés sur les moyens linguistiques employés lors de cette restructuration et sur les objectifs des journalistes concernés. S'agissait-il de créer une nouvelle image du président russe ou de l'adapter à l'image existant depuis plusieurs années qui serait, par conséquent, plus facile à faire passer auprès des lecteurs?

Dans l'optique comparative, notre réflexion a donc porté sur trois axes : la mise en situation du lecteur; la sélection des thèmes présentés au public parmi ceux abordés par Vladimir Poutine ; l'étude des procédés linguistiques utilisés pour reconstituer les questions des journalistes et les réponses de Vladimir Poutine, observant ainsi comment le transfert des informations du russe vers une autre langue a pu entraîner des inexactitudes et avoir un impact sur l'image du président russe.

\section{NOTES}

1. Ramonet I. « Le cinquième pouvoir » Le Monde diplomatique, octobre 2003.

2. Conan E., Dély R. « La nouvelle pensée unique » Marianne, n578, 2008, p. 20.

\section{AUTEURS}

\section{VALÉRY KOSSOV}

ILCEA / GREMUTS

ÉLISABETH LAVAULT-OLLÉON

ILCEA / GREMUTS 